\title{
Central aortic pressure, arterial stiffness and echocardiographic parameters of children with overweight/obesity and arterial hypertension
}

\author{
Jerzy Wójtowicz , A-D, F, Aleksandra Łempicka1, B, C, E , Włodzimierz Łuczyński1 B, B, E, F, Wojciech Szczepański1, A-C, E, F, \\ Aleksandra Zomerfeld ${ }^{1, B}$, Kornel Semeran ${ }^{1, B, E}$, Artur Bossowski ${ }^{1, F}$ \\ ${ }^{1}$ Department of Pediatrics, Endocrinology, Diabetology with Cardiology Divisions, Medical University of Bialystok, Poland \\ A - research concept and design; B - collection and/or assembly of data; C - data analysis and interpretation; \\ $D$ - writing the article; $E$ - critical revision of the article; $F$ - final approval of the article
}

Address for correspondence

Wojciech Szczepański

E-mail:wojciechsz@op.pl

Funding sources

Grant No. 133-42806L from the Medical

University of Bialystok, Poland.

Conflict of interest

None declared

Received on March 24, 2016

Reviewed on August 9, 2016

Accepted on September 30, 2016
DOI

10.17219/acem/65485

Copyright

Copyright by Author(s)

This is an article distributed under the terms of the

Creative Commons Attribution Non-Commercial License

(http://creativecommons.org/licenses/by-nc-nd/4.0/)

\section{Abstract}

Background. A non-invasive estimation of central aortic pressure and echocardiographic parameters, and appropriate interpretation thereof make it possible to determine the status of the vascular wall and myocardium. These parameters are early markers of unfavorable remodeling of the cardiovascular system.

Objectives. The aim of this study was to analyze the central aortic pressure and echocardiographic parameters of overweight/obese children (with or without concomitant arterial hypertension).

Material and methods. The study included 84 children (mean age: 15 years) - 45 with primary arterial hypertension, 39 normotensive, and 38 controls. Central aortic systolic (CSys) and diastolic (CDia) pressures, pulse wave augmentation index (Aix@75), peripheral resistance, pulse wave reflection and pulse wave velocity (PWV) were determined by means of brachial oscillometry. A number of echocardiographic parameters were recorded.

Results. Obese children with arterial hypertension showed the highest values of CSys, CDia and PWV, as well as interventricular septal end-diastolic thickness (IVS), left atrial diameter (LAD), left ventricular mass index (LVMI), elongation index and cardiac output (CO). Patient age, CSYS, CDIA and LAD were identified as significant predictors of PWV. The groups did not differ in terms of Aix@75, peripheral resistance and pulse wave reflection values.

Conclusions. Children with overweight/obesity present with elevated values of cSys, PWV, LVMI, LAD and C0. The risk of these abnormalities is further increased due to concomitant arterial hypertension.

Key words: pulse wave velocity, arterial stiffness, obesity, arterial hypertension, echocardiography 


\section{Introduction}

The methods for early assessment of cardiovascular risk in children are gaining increasing interest.

The process of atherosclerosis may already begin in early childhood. ${ }^{1}$ Obesity and arterial hypertension are established risk factors of early atherosclerosis and its cardiovascular complications. ${ }^{2}$ The incidence of obesity and hypertension among children and adolescents is still increasing. ${ }^{3}$ Due to their high incidence and severe systemic complications, both diseases are considered a serious social problem. ${ }^{4}$ This substantiates research on non-invasive markers of early cardiovascular changes that could be used in patients at increased risk.

Determination of arterial blood pressure is a routine component of physical examination. Many previous studies have shown that arterial blood pressure correlates with cardiovascular risk. However, conventional measurement provides information only on blood pressure in peripheral arteries. More accurate data on vascular wall status can be obtained due to determination of central aortic pressure and pulse wave analysis. ${ }^{5}$ Despite the availability of non-invasive methods for central aortic pressure determination, this parameter is not routinely considered in clinical practice, and the number of published results of non-invasive examination of the cardiovascular system in children with obesity and concomitant arterial hypertension is fairly limited. 5,6 Furthermore, the results of the sparse available studies dealing with the problem in question are inconclusive. ${ }^{7-9}$ The issue whether hypertension changes central aortic pressure parameter values remains open.

The aim of this study was to analyze the central aortic pressure and echocardiographic parameters of overweight/obese children (with or without concomitant primary arterial hypertension) and to investigate the relationship between obesity and hypertension and central blood pressure and echocardiographic parameters.

\section{Material and methods}

The study included 84 children and adolescents aged between 10 and 18 years (mean age: 15 years). The in-

Table 1. Median values, lower and upper quartiles (25:75) of age, height and body mass index in the analyzed groups of children

\begin{tabular}{|c|c|c|c|c|}
\hline Variable & $\begin{array}{l}\text { Control group } \\
\qquad \begin{array}{l}n=38 \\
\text { (group I) }\end{array}\end{array}$ & $\begin{array}{c}\text { Obesity and } \\
\text { hypertension } \\
n=45 \\
\text { (group II) }\end{array}$ & $\begin{array}{l}\text { Obesity without } \\
\text { hypertension } \\
n=39 \\
\text { (group III) }\end{array}$ & $p$-value \\
\hline Age (years) & $16(13: 17)$ & $15(14: 16)$ & $16(12: 17)$ & ns \\
\hline Sex & $\begin{array}{c}\text { male }-20 \\
\text { female }-19\end{array}$ & $\begin{array}{c}\text { male }-26 \\
\text { female }-19\end{array}$ & $\begin{array}{c}\text { male - } 17 \\
\text { female }-22\end{array}$ & ns \\
\hline Height (cm) & 165 (159:176) & 171 (157:182) & $164(158: 170)$ & ns \\
\hline $\begin{array}{l}\text { BMI } \\
\text { SDS }\end{array}$ & $\begin{array}{c}-0.11 \\
(-0.67: 0.39)\end{array}$ & $\begin{array}{c}2.76 \\
(1.49: 4.98)\end{array}$ & $\begin{array}{c}3.84 \\
(2.37: 5.25)\end{array}$ & $\begin{array}{l}\text { II vs } \mid p<0.0001 \\
\text { III vs I } p<0.0001\end{array}$ \\
\hline
\end{tabular}

vestigational group included children with overweight/ obesity, among them individuals with primary arterial hypertension $(n=45)$ and a subset of normotensive subjects $(n=39)$. The control group comprised children with normal body weight and no history of arterial hypertension $(\mathrm{n}=38)$ (Table 1). Children with structural cardiac abnormalities, established arrhythmia or organic etiology of arterial hypertension were excluded from the study. ${ }^{6}$

The following data was noted in all patients: anthropometric parameters (weight, height, waist circumference, standardized body mass index - BMI SDS), blood pressure (including central) and echocardiography.

The measurements were performed just after the diagnosis of arterial hypertension had been established before any pharmacotherapy. The anthropometric data of the study participants was referenced against the recently updated standards for Polish children, including weight percentile charts according to sex and age (Polish nationwide OLAF project). ${ }^{10}$ Underweight was defined as BMI SDS $\leq-1$, normal body weight as $1>$ BMI SDS > -1 , overweight as $2>\mathrm{BMI}$ SDS $\geq 1$, and obesity as BMI SDS $\geq 2$. The intra- and inter-observer coefficient of variation was $1.0 \%$ and $1.5 \%$ (respectively) for height, $0.8 \%$ and $1.1 \%$ for weight, $1.6 \%$ and $1.6 \%$ for waist circumference, and $2.2 \%$ and $2.8 \%$ for blood pressure.

Patients with arterial hypertension were identified on the basis of blood pressure tables for children and adolescents according to age, sex, and body height, by 3 ambulatory measurements with $24 \mathrm{~h}$ blood pressure monitoring confirmation. ${ }^{11}$ All the study participants were subjected to central aortic pressure determination and echocardiographic examination.

Central aortic pressure was determined by means of brachial oscillometry with a Mobil-o-Graph device (I.E.M. GmbH, Stolberg, Germany) with inbuilt ARC-Solver algorithm (brachial waveform). Central aortic systolic (cSys) and diastolic (cDia) pressures were determined, along with pulse wave augmentation index (Aix@75), peripheral resistance, pulse wave reflection and pulse wave velocity (PWV), all adjusted to sex, age and height.,12,13 The measurements were taken in the morning hours, at least $30 \mathrm{~min}$ after the last meal. A total of 4 measurements per person were taken at 15 min intervals with the patient in a sitting position.

Echocardiographic examination was conducted with a Toshiba Istyle aplio MX SSA 780A device (Toshiba, Minato, Japan) by a single experienced cardiologist who did not know that children were included into this study. Interventricular septal enddiastolic thickness (IVS), left ventricular end-diastolic diameter (LVDd), left ventricular posterior wall thickness (PWT), left ventricular end-systolic diameter (LVDs) and left atrial diameter (LAD) were determined as proposed by Kampmann et al. ${ }^{14}$ 
The above-mentioned data was used to calculate relative wall thickness $($ RWT $=($ IVS + PWT $):$ LVDd $)$ and left ventricular ejection fraction (EF). Left ventricular mass index (LVMI) was calculated using the formula by AV-Cube: LV mass $(\mathrm{g})=0.8 \times\left[1.04 \times(\mathrm{LVDd}+\mathrm{IVS}+\mathrm{PWT})^{3}-\mathrm{LVDd}^{3}\right] \times$ $0.001+0.6$. LV mass (LVM) was indexed for body height (LVMI), using height to the allometric power of 2.7 in order to minimize the contribution of body size to $\mathrm{LVH}^{15}$

Table 2. Median values, lower and upper quartiles (25:75) of hemodynamic parameters determined on the basis of central aortic pressure measurement in the analyzed groups of children

\begin{tabular}{|c|c|c|c|c|}
\hline Variable & $\begin{array}{l}\text { Control group } \\
\qquad \begin{array}{l}n=38 \\
\text { (group I) }\end{array}\end{array}$ & $\begin{array}{l}\text { Obesity and } \\
\text { hypertension } \\
n=45 \\
\text { (group II) }\end{array}$ & $\begin{array}{l}\text { Obesity without } \\
\text { hypertension } \\
n=39 \\
\text { (group III) }\end{array}$ & $p$-value \\
\hline $\begin{array}{l}\text { cSys } \\
\text { (mm Hg) }\end{array}$ & $\begin{array}{c}103 \\
(97: 109)\end{array}$ & $\begin{array}{c}116 \\
(106: 121)\end{array}$ & $\begin{array}{c}110 \\
(101: 115)\end{array}$ & $\begin{array}{c}\| \text { vs } \mid p<0.0001 \\
\text { II vs III } p<0.05 \\
\text { III vs } \mid p<0.05\end{array}$ \\
\hline $\begin{array}{l}\text { cDia } \\
(\mathrm{mm} \mathrm{Hg})\end{array}$ & $\begin{array}{c}72 \\
(65: 77)\end{array}$ & $\begin{array}{c}79 \\
(71: 89)\end{array}$ & $\begin{array}{c}76 \\
(69: 82)\end{array}$ & II vs $\mid p<0.05$ \\
\hline $\begin{array}{l}\text { Aix@75 } \\
(\%)\end{array}$ & $\begin{array}{c}19.5 \\
(13.7: 25.2)\end{array}$ & $\begin{array}{c}20.5 \\
(13.0: 27.0)\end{array}$ & $\begin{array}{c}21.0 \\
(14.0: 29.0)\end{array}$ & ns \\
\hline $\begin{array}{l}\text { Peripheral } \\
\text { resistance } \\
\text { (s.mm Hg/mL) }\end{array}$ & $\begin{array}{c}1.1 \\
(1.0: 1.2)\end{array}$ & $\begin{array}{c}1.2 \\
(1.1: 1.3)\end{array}$ & $\begin{array}{c}1.2 \\
(1.1: 1.3)\end{array}$ & ns \\
\hline $\begin{array}{l}\text { Pulse wave } \\
\text { reflection } \\
\text { (\%) }\end{array}$ & $\begin{array}{c}58 \\
(48: 62)\end{array}$ & $\begin{array}{c}55 \\
(50: 62)\end{array}$ & $\begin{array}{c}58 \\
(49: 64)\end{array}$ & ns \\
\hline $\begin{array}{l}\text { PWV } \\
(\mathrm{m} / \mathrm{s})\end{array}$ & $\begin{array}{c}4.7 \\
(4.5: 4.9)\end{array}$ & $\begin{array}{c}5.2 \\
(4.6: 5.5)\end{array}$ & $\begin{array}{c}4.9 \\
(4.6: 5.6)\end{array}$ & $\begin{array}{c}\| \text { vs } \mid p<0.0001 \\
\| \text { vs } \| \mid p<0.05\end{array}$ \\
\hline
\end{tabular}

Table 3. Median values, lower and upper quartiles (25:75) of echocardiographic parameters in the analyzed groups of children

\begin{tabular}{|c|c|c|c|c|}
\hline Variable & $\begin{array}{l}\text { Control group } \\
\text { (group I) }\end{array}$ & $\begin{array}{l}\text { Obesity with } \\
\text { hypertension } \\
\text { (group II) }\end{array}$ & $\begin{array}{l}\text { Obesity without } \\
\text { hypertension } \\
\text { (group III) }\end{array}$ & $\mathrm{p}$-value \\
\hline $\begin{array}{l}\text { IVS } \\
(\mathrm{mm})\end{array}$ & $\begin{array}{c}7.9 \\
(6.2: 8.9)\end{array}$ & $\begin{array}{c}8.9 \\
(7.6: 9.7)\end{array}$ & $\begin{array}{c}8.0 \\
(7.6: 8.7)\end{array}$ & II vs $\mid p<0.05$ \\
\hline $\begin{array}{l}\text { LVDd } \\
\text { Z-score }\end{array}$ & $\begin{array}{c}1.26 \\
(0.32: 1.74)\end{array}$ & $\begin{array}{c}0.64 \\
(-0.20: 1.70)\end{array}$ & $\begin{array}{c}0.53 \\
(-0.49: 1.37)\end{array}$ & ns \\
\hline $\begin{array}{c}\text { LAD } \\
\text { Z-score }\end{array}$ & $\begin{array}{c}0.45 \\
(0.00: 1.00)\end{array}$ & $\begin{array}{c}0.90 \\
(0.05: 1.73)\end{array}$ & $\begin{array}{c}0.85 \\
(0.09: 1.75)\end{array}$ & $\begin{array}{c}\text { II vs } \mid p<0.0001 \\
\text { III vs } \mid p<0.001\end{array}$ \\
\hline LVMI > $95 \mathrm{pc}$ & 0 & 18 (45\%) & $5(14 \%)$ & \\
\hline RWT & $\begin{array}{c}0.33 \\
(0.30: 0.36)\end{array}$ & $\begin{array}{c}0.34 \\
(0.31: 0.37)\end{array}$ & $\begin{array}{c}0.32 \\
(0.30: 0.34)\end{array}$ & ns \\
\hline RWT > 0.41 & $n=0$ & $n=2$ & $n=1$ & \\
\hline $\begin{array}{l}\mathrm{EF} \\
(\%)\end{array}$ & $\begin{array}{c}68 \\
(66: 72)\end{array}$ & $\begin{array}{c}68 \\
(65: 72)\end{array}$ & $\begin{array}{c}69 \\
(64: 73)\end{array}$ & ns \\
\hline $\begin{array}{l}\text { SV } \\
(\mathrm{mL})\end{array}$ & $\begin{array}{c}61.9 \\
(42.3: 87.9)\end{array}$ & $\begin{array}{c}82.3 \\
(52.5: 101)\end{array}$ & $\begin{array}{c}76.5 \\
(52.9: 91.4)\end{array}$ & ns \\
\hline $\begin{array}{c}\mathrm{HR} \\
(\mathrm{bpm})\end{array}$ & $\begin{array}{c}70 \\
(56: 74)\end{array}$ & $\begin{array}{c}72 \\
(58: 87)\end{array}$ & $\begin{array}{c}74 \\
(62: 87)\end{array}$ & ns \\
\hline $\begin{array}{c}\mathrm{CO} \\
(\mathrm{L} / \mathrm{min})\end{array}$ & $\begin{array}{c}4.11 \\
(3.44: 5.44)\end{array}$ & $\begin{array}{c}6.50 \\
(5.02: 7.30)\end{array}$ & $\begin{array}{c}5.53 \\
(4.02: 6.63)\end{array}$ & $\|$ vs $\mid p<0.05$ \\
\hline
\end{tabular}

The $95^{\text {th }}$ percentile for LVMI and the upper normal limit for RWT were defined according to Daniels et al. ${ }^{16}$

Furthermore, stroke volume (SV), heart rate (HR) and cardiac output (CO) were determined on the basis of Doppler flow analysis. ${ }^{17}$

The results were recorded in a Microsoft Access for Windows database and subjected to statistical analysis with STATISTICA v. 10.0 (StatSoft, Inc., Tulsa, USA) and GraphPad Prism v. 5.0 (GraphPad Software, Inc., La Jolla, USA) packages. As the data lacked normal distribution (as shown with the Kolmogorov-Smirnov and Shapiro-Wilk tests), one-way analysis of variance (ANOVA Kruskal-Wallis) and post hoc-tests were used for intergroup comparisons. The power and direction of the relationships between pairs of analyzed variables were determined on the basis of the Spearman's coefficients of rank correlation. Multivariate linear regression analysis was used to evaluate the impact of clinical parameters on basic hemodynamic values (e.g., PWV). The threshold of statistical significance for all the tests was set at $\mathrm{p}<0.05$. The results are presented as medians, along with lower and upper quartiles.

\section{Results}

The children from the investigational group did not differ from the controls in terms of age, sex and height characteristics (Table 1).

The parameters of central aortic pressure, determined by means of applanation tonometry, are presented in Table 2. Obese children with concomitant arterial hypertension showed the highest values of cSys and cDia. Obese normotensive subjects also presented with significantly higher cSys than the controls. The analyzed groups did not differ significantly in terms of such pulse wave parameters as Aix@75, peripheral resistance or pulse wave reflection. However, significantly higher values of PWV were found in obese hypertensive children when compared to both the controls and normotensive patients with obesity.

The results of the comparative analysis of echocardiographic parameters are presented in Table 3. Children and adolescents with overweight/obesity and concomitant arterial hypertension showed significantly higher values of IVS and LVMI than did 
Table 4. Correlation coefficient of PWV, Aix@75, LVMI, LAD, and CO

\begin{tabular}{|c|c|c|c|c|c|}
\hline Variable & PWV (m/s) & Aix@75 (\%) & LVMI (g/ht $\left.{ }^{2.7}\right)$ & $\mathrm{LAD}(\mathrm{mm})$ & $\mathrm{CO}(\mathrm{L} / \mathrm{min})$ \\
\hline BMI SDS & $0.35^{*}$ & -0.04 & $0.42^{*}$ & $0.49^{*}$ & $0.50^{*}$ \\
\hline cSys (mmHg) & $0.94^{*}$ & 0.01 & $0.41^{*}$ & $0.40^{*}$ & 0.33 \\
\hline cDia $(\mathrm{mmHg})$ & $0.45^{*}$ & $0.34^{*}$ & 0.13 & 0.16 & 0.13 \\
\hline PWV (m/s) & - & -0.12 & 0.18 & $0.39 *$ & $0.40^{*}$ \\
\hline Aix@75 (\%) & -0.12 & - & -0.13 & $-0.38^{*}$ & -0.16 \\
\hline LVMI (g/ht $\left.{ }^{2.7}\right)$ & 0.18 & -0.13 & - & $0.52^{*}$ & 0.33 \\
\hline LAD (mm) & $0.39 *$ & $-0.38^{*}$ & $0.52^{*}$ & - & $0.56^{*}$ \\
\hline $\mathrm{CO}(\mathrm{L} / \mathrm{min})$ & $0.40^{*}$ & -0.16 & 0.33 & $0.56^{*}$ & - \\
\hline
\end{tabular}

$* p<0.001$.

the controls. Moreover, they presented with significantly higher CO. Normotensive children with overweight/obesity also showed higher values of LVMI and LAD when compared to the controls.

We found a number of significant correlations between the analyzed anthropometric and hemodynamic parameters (Table 4). After the analysis of these correlations, 2 regression models were developed to explain the sources of variance in cardiovascular risk markers: PWV and Aix@75. We showed that patient age, cSys, cDia and LAD explained up to $91 \%$ of variance in PWV ( $p<0.0001)$. In turn, patient age and sex, HR, LV mass, LAD and cDia were identified as significant predictors of Aix@75, explaining up to $41 \%$ of variance in this parameter. Both models turned out to be statistically significant after stratification of patients according to their body weight and incidence of arterial hypertension.

\section{Discussion}

Our findings suggest that children with overweight/ obesity and hypertension present with higher values of pulse wave velocity and cardiac output. All overweight/ obese children had high LVMI and LAD. Central aortic systolic pressure was higher not only in overweight/obese hypertensive children but also in the overweight/obese peripheral normotensive group. These findings may contribute to increased risk for arterial stiffness in this group of patients.

Central aortic pressure depends on stroke volume, peripheral resistance and elastic properties of arteries. Pulse wave velocity and augmentation index represent well-established markers of arterial stiffness. ${ }^{7,18}$ Pulse wave velocity is an outcome of arterial elasticity and rigidity. Augmentation index is also a blood pressure-independent measure of arterial elasticity. Obesity is known to be associated with greater arterial stiffness and increased incidence of cardiovascular disease in adulthood. ${ }^{2,19}$ Our findings are consistent with the results of previous studies, in which children and adolescents with overweight/obesity presented with higher values of PWV than their peers with normal body weight. ${ }^{8,9,20}$ One previous study demonstrated a correlation between PWV and continuous metabolic syndrome score in Indian children. ${ }^{21}$ This evidence suggests that obesity may be an independent factor affecting the status of the vascular wall. However, this association is likely diseasestage specific, as it was shown to be particularly strong in adult patients with angiographic evidence of changes in coronary arteries. ${ }^{22}$

In our study, children with obesity and arterial hypertension presented with significantly higher values of PWV when compared to both controls and obese normotensive subjects. There were no statistically significant differences in PWV between obese normotensives and controls. Elevated arterial blood pressure in childhood has been demonstrated to be a consistent predictor of arterial stiffness in otherwise asymptomatic young adults. ${ }^{23}$ The presence of arterial hypertension or even prehypertension in childhood/adolescence is a predictor of cardiovascular impairment during early adulthood. ${ }^{7}$

We identified cSys, cDia, LAD and patient age as significant predictors of variance in PWV. An association between PWV and age was previously demonstrated in a large group of children. ${ }^{24}$ Despite the positive correlation between PWV and BMI observed in our sample (Table 4), the latter did not prove to be a significant predictor of PWV on regression analysis. Other authors have documented associations between PWV and other markers of cardiovascular risk such as preperitoneal fat tissue thickness and waist/hip circumference. ${ }^{8,22}$ However, we did not include these parameters in our analysis.

AS can be also quantified on the basis of augmentation index, Aix@75..$^{5}$ This parameter turned out to be correlated with the presence of obesity and coronary artery disease in adults. ${ }^{22}$ In the case of children and adolescents, this association was more evident in patients with arterial hypertension than in obese individuals. ${ }^{7,9}$ However, we did not find a similar relationship in our material; the only predictors of Aix@75, both in the whole group of children and in their subsets with/without overweight/obesity and arterial hypertension, were age, sex, HR, LV mass, LAD and cDia. 
Central aortic pressure exerts a direct effect on left ventricular load. LV overload leads to myocardial hypertrophy and is associated with increased risk of myocardial ischemia. ${ }^{25}$ In our study, children with overweight/obesity presented with significantly higher values of LVMI than their peers with normal body weight (Table 3). In contrast, we did not find significant differences in the LVMI values of overweight/obese patients with or without concomitant arterial hypertension. Obese children whose arterial blood pressure level did not correspond to hypertension presented with significantly higher values of central aortic systolic pressure (cSys) than did the normotensive subjects. LVMI exceeded the $95^{\text {th }}$ percentile for this parameter, proposed by Daniels et al., in up to $45 \%$ of children with arterial hypertension and in only $14 \%$ of normotensive obese subjects (Table 3). ${ }^{16}$ According to some authors, the LVMI of children and adolescents with primary hypertension correlates significantly with their $24 \mathrm{~h}$ systolic blood pressure. ${ }^{26}$ The authors of another study found left ventricular hypertrophy (LVH) in 30\% of obese adolescents at mean age $<18$ years, despite a low prevalence of arterial hypertension in this group. ${ }^{27}$ Aside from higher mean ambulatory blood pressure levels, children with arterial hypertension and LVH may also present with higher mean BMI Z-scores when compared to LVHfree individuals. ${ }^{28}$ Therefore, left ventricular hypertrophy seems to result from the influence of metabolic and hormonal factors associated with obesity, rather than from arterial hypertension itself. Previous studies of children, adolescents and young adults showed that both obesity and systolic blood pressure correlate significantly with the incidence of left ventricular hypertrophy, and showed weaker associations between LVH and other components of the metabolic syndrome. ${ }^{29}$

We found strong correlations between LVMI, cSys, BMI SDS and LAD (Table 4). However, similar to previous studies, we did not observe an association between LVMI and cDia. ${ }^{26}$ Moreover, we did not demonstrate significant correlations between LVMI, PWV and Aix@75. Adult patients with pharmacologically controlled arterial hypertension were shown to present with normal left ventricular mass, which correlated significantly with PWV, but not Aix@75.30

The type of left ventricular remodeling may also have its unfavorable prognostic implications. ${ }^{6}$ Children and adolescents with increased left ventricular mass show a variable degree of concentric/eccentric hypertrophy and concentric remodeling. Most of our patients with LVH presented with eccentric hypertrophy, and only sporadically did their RWT values exceed 0.41 (Table 3). According to the literature, patients with concentric hypertrophy are characterized by higher BMI Z-scores, while those with eccentric hypertrophy present with higher values of systolic blood pressure and larger left atrial diameters. ${ }^{28}$ Due to the small number of patients with concentric hypertrophy, we did not conduct a similar comparative analysis in our sample.
Despite the lack of clinical symptoms and normal ejection fraction, LV hypertrophy is associated with development of left ventricular diastolic dysfunction. ${ }^{4,7}$ An alteration of LV geometry leads to changes in aortic diameter and coexists with enlargement of the left atrium. Left ventricular diastolic dysfunction was observed in children and adolescents with obesity, as well as in subjects with arterial hypertension. ${ }^{7,29}$ In our study, both groups of obese children presented with significantly higher left atrial diameters (LAD) despite the lack of significant changes in ejection fraction. Enlargement of the left atrium is known to correlate with BMI, systolic blood pressure and left ventricular mass in children and adolescents. ${ }^{29}$ We observed such correlations in our sample, along with associations between LAD, PWV and Aix@75 (Table 4). However, it should be stressed that left atrial diameter reflects the volume of circulating blood. This was confirmed in our study, as children with overweight/ obesity presented with higher values of cardiac output than their peers with normal body weight.

Our study showed that children with overweight/obesity present with elevated values of central aortic systolic pressure, pulse wave velocity, left ventricular mass index, left atrial diameter and cardiac output. The risk of these abnormalities is further increased due to concomitant arterial hypertension. The abovementioned changes may correspond to early stages of unfavorable remodeling of the cardiovascular system in young patients. This substantiates routine determination of central systolic aortic pressure, PWV and selected echocardiographic parameters (IVS, LAD) in overweight/obese children. Such attitude could be helpful in the identification of patients at increased risk of cardiovascular dysfunction and its complications, and would result in an intensification of preventive and therapeutic measures in this group.

\section{Limitations}

A non-invasive estimation of the central aortic pressure was used.

\section{References}

1. Järvisalo MJ, Jartti L, Näntö-Salonen $K$, et al. Increased aortic intima-media thickness: A marker of preclinical atherosclerosis in high-risk children. Circulation. 2001;104:2943-2947.

2. Catala-Lopez F, Genova-Maleras R. Disease burden attributable to major risk factors in western European countries: The challenge of controlling cardiovascular risk factors. Rev Esp Cardiol (EnglEd). 2013;66:591-593.

3. Kwiterovich PO. Clinical and laboratory assessment of cardiovascular risk in children: Guidelines for screening, evaluation, and treatment. J Clinical Lipidology. 2008;2:248-266.

4. Mancia G, Fagard R, Narkiewicz K, et al. 2013 ESH/ESC guidelines for the management of arterial hypertension: The task force for the management of arterial hypertension of the European Society of Hypertension (ESH) and of the European Society of Cardiology (ESC). Eur Heart J. 2013;34:2159-2219.

5. Lowenthal A, Evans JM, Punn R, et al. Arterial applanation tonometry: Feasibility and reproducibility in children and adolescents. Am J Hypertens. 2014;27:1218-1224. 
6. Weiss W, Gohlisch C, Harsch-Gladisch C, Tölle M, Zidek W, van der Giet M. Oscillometric estimation of central blood pressure: Validation of the Mobil-O-Graph in comparison with the SphygmoCor device. Blood Press Monit. 2012;17:128-131.

7. Urbina EM, Khoury PR, McCoy C, Daniels SR, Kimball TR, Dolan LM. Cardiac and vascular consequences of pre-hypertension in youth. J Clin Hypertens. 2011;13:332-342.

8. Hacihamdioglu B, Ocal G, Berberoglu M, et al. Preperitoneal fat tissue may be associated with arterial stiffness in obese adolescents. Ultrasound Med Biol. 2014;40:871-876.

9. Pierce GL, Zhu H, Darracott K, et al. Arterial stiffness and pulse-pressure amplification in overweight/obese African-American adolescents: Relation with higher systolic and pulse pressure. Am J Hypertens. 2013;26:20-26.

10. Kułaga Z, Litwin M, Tkaczyk M, et al. Polish 2010 growth references for school-aged children and adolescents. Eur J Pediatr. 2011;170:599-609.

11. National High Blood Pressure Education Program Working Group on High Blood Pressure in Children and Adolescents. The fourth report on the diagnosis, evaluation, and treatment of high blood pressure in children and adolescents. Pediatrics. 2004;114:555-576.

12. Weber $T$, Wassertheurer $S$, Rammer M, et al. Validation of a brachial cuff-based method for estimating central systolic blood pressure. Hypertension. 2011;58:825-832.

13. Cheng HM, Wang KL, Chen YH, Yin FCP, Chou P, Chen CH. Estimation of central systolic blood pressure using an oscillometric blood pressure monitor. Hypertens Res. 2010;33:592-599.

14. Kampmann C, Wiethoff C, Wenzel A, et al. Normal values of $M$ mode echocardiographic measurements of more than 2000 healthy infants and children in central Europe. Heart. 2000;83:667-672.

15. Chirinos JA, Segers $P$, de Buyzere ML, et al. Left ventricular mass: Allometric scaling, normative values, effect of obesity and prognostic performance. Hypertension. 2010;56:91-98.

16. Daniels SR, Loggie JM, Khoury P, Kimball TR. Left ventricular geometry and severe left ventricular hypertrophy in children and adolescents with essential hypertension. Circulation. 1998;97:1907-1911.

17. Dubin J, Wallerson DC, Cody RJ, Devereux RB. Comparative accuracy of Doppler echocardiuographic methods for clinical stroke volume determination. Am Heart J. 1990;120:116-123.

18. Kawai T, Ohishi M, Onishi M, et al. Cut-off value of brachial-ankle pulse wave velocity to predict cardiovascular disease in hypertensive patients: A cohort study. J Atheroscler Thromb. 2013;20:391-400.

19. Xiong Z, Zhu C, Zheng Z, et al. Relationship between arterial stiffness assessed by brachial-ankle pulse wave velocity and coronary artery disease severity assessed by the SYNTAX score. J Atheroscler Thromb. 2012;19:970-976.

20. Pandit DS, Khadilkar AV, Chiplonkar SA, Khadilkar VV, Kinare AS Arterial stiffness in obese children. Role of adiposity and physical activity. J Endocrinol Metab. 2014;18:70-76.

21. Pandit D, Chiplonkar S, Khadilkar A, Kinare A, Khadilkar V. Efficacy of a continuous metabolic syndrome score in Indian children for detecting subclinical atherosclerotic risk. Int J Obes. 2011;35:1318-1324.

22. Bechlioulis A, Vakalis K, Naka KK, et al. Increased aortic pulse wave velocity is associated with the presence of angiographic coronary artery disease in overweight and obese patients. Am J Hypertens. 2013;26:265-270.

23. Aatola H, Magnussen CG, Koivistoinen T, et al. Simplified definition of elevated pediatric blood pressure and high adult arterial stiffness. Pediatrics. 2013;132:70-76.

24. Hidvegi EV, Illyes $M$, Benczúr $B$, et al. Reference values of aortic pulse wave velocity in a large healthy population aged between 3 and 18 years. J Hypertens. 2012;30:2314-2321.

25. Verdecchia P, Carini G, Circo A, et al. Left ventricular mass and cardiovascular morbidity in essential hypertension: The MAVI study. J Am Coll Cardiol. 2001;38:1829-1835.

26. Richey PA, DiSessa TG, Hastings MC, Somes GW, Alpert BS, Jones DP. Ambulatory blood pressure and increased left ventricular mass in children at risk for hypertension. J Pediatr. 2008;152:343-348.

27. Chinali M, de Simone G, Roman MJ, et al. Impact of obesity on cardiac geometry and function in a population of adolescents: The Strong Heart Study. J Am Coll Cardiol. 2006;47:2267-2273.
28. Richey PA, DiSessa TG, Somes GW, Alpert BS, Jones DP. Left ventricular geometry in children and adolescents with primary hypertension. Am J Hypertens. 2010;23:25-29.

29. Chinali M, de Simone G, Roman MJ, et al. Cardiac markers of preclinical disease in adolescents with the metabolic syndrome: The Strong Heart Study. J Am Coll Cardiol. 2008;52:932-938.

30. Rabkin SW, Chan SH. Correlation of pulse wave velocity with left ventricular mass in patients with hypertension once blood pressure has been normalized. Heart Int. 2012;7:27-31. 